\title{
Special Issue "International Conference of Spirituality in Healthcare. Nurturing the Spirit"-Trinity College Dublin 2016
}

\author{
Fiona Timmins ${ }^{1, *,+}$, Richard Egan $^{2}$, Bernadette Flanagan ${ }^{3,+}$, Yvonne Muldowney ${ }^{1,+}$, \\ Colm OBoyle ${ }^{1,+}$, Vivienne Brady ${ }^{1,+}{ }^{(\mathbb{D}}$, Jacqueline Whelan ${ }^{1,+}$, Kathleen Neenan ${ }^{1,+}$ and \\ Wilfred McSherry $4,5,6,+$ \\ 1 School of Nursing and Midwifery, Trinity College Dublin, 24 D'Olier Street, Dublin 2, Ireland; \\ muldowy@tcd.ie (Y.M.); coboyle@tcd.ie (C.O.); bradyvi@tcd.ie (V.B.); whelanj1@tcd.ie (J.W.); \\ kaneenan@tcd.ie (K.N.) \\ 2 Department of Preventive and Social Medicine (DSM), Dunedin School of Medicine, University of Otago, \\ Dunedin 9054, New Zealand; richard.egan@otago.ac.nz \\ 3 Waterford Institute of Technology, Waterford, Ireland; bflanagan@wit.ie \\ 4 Department of Nursing, School of Health and Social Care, Staffordshire University, Blackheath Lane, \\ Stafford ST18 0AD, UK; W.McSherry@staffs.ac.uk \\ 5 The University Hospitals of North Midlands NHS NHS Trust, Newcastle Rd, Stoke-on-Trent ST4 6QG, UK \\ 6 VID vitenskapelige høgskole, Haraldsplass Bergen, Ulriksdal 10, 5009 Bergen, Norway \\ * Correspondance: timminsf@tcd.ie; Tel.: +353-1-896-3699 \\ + These authors contributed equally to this work.
}

Received: 12 September 2017; Accepted: 13 September 2017; Published: 26 September 2017

This is an editorial of a Special Issue regarding the International Conference of Spirituality in Healthcare held in the School of Nursing and Midwifery, Trinity College Dublin, Republic of Ireland (ROI), on June 2016 (Spirituality Research and Innovation Group 2016). This event was the second international spirituality in healthcare conference hosted by Trinity College Dublin, with a third international conference planned for 22 June 2018. Conferences such as this provide a unique opportunity for academics and clinicians in healthcare to share their research findings, clinical practice and emerging ideas. The conference is international and multidisciplinary and as such provides a novel space and platform for discussion and debate on the topic. The editorial draws together a selection of published papers, arising from the conference; collectively these demonstrate a continuing and growing interest in the subject of spiritualty in healthcare.

\section{Embracing Spirituality across International Healthcare Contexts}

This Special Issue, related to the conference, features a range of international papers with a particular focus on spirituality and spiritual care concerns within healthcare. It is clear that the topic of spirituality is gathering attention in a variety of diverse fields across healthcare internationally. It is obvious from these discussions that the concept of spirituality is not new within healthcare (Keenan 2017; Romeiro et al. 2017). Rather it has long been considered best practice to ensure that responses within healthcare, across all phases of life, are holistic and address the human physical, psychological, social and spiritual aspects (Keenan 2017; Romeiro et al. 2017; Egan et al. 2011). However, what is novel is that spirituality is now receiving unprecedented attention within international healthcare research, evidenced for example by Egan et al. (Egan et al. 2011) first national study of nurses views on spirituality within healthcare in New Zealand. Furthermore, while spirituality is traditionally associated with end of life care (Romeiro et al. 2017; Velosa et al. 2017) these papers reflect the widening and diverse application of spirituality in areas such as intellectual disability, day surgery, infertility and dietetics (Romeiro et al. 2017; Keenan and MacDermott 2016; Pike 2017; Patel et al. 2017). 
In keeping with contemporary understandings of spirituality, these papers generally refer to spirituality as a sense of connecting with others, transcendence and finding meaning and purpose in life (Velosa et al. 2017; Weathers et al. 2015; La Cour and Hvidt 2010). Transcendence in this sense refers to the concept of a higher or greater purpose in life; a sense of what it is important to do and what constitutes a good or a right way to live. By providing spiritual care, healthcare workers can support an individual's quest for meaning making during particular life events, such as undergoing day surgery or to aid people to improve their self-worth, find support from their faith perhaps assisting them to eat better and lose weight (Patel et al. 2017).

Although it is pointed out that while the aforementioned underpinning definitions inform many of the discussions and research published in this issue we are also reminded that little overall consensus on definitions of spirituality exists (Egan et al. 2011; Velosa et al. 2017). There are also inconsistencies, lack of direction and lack of education in relation to healthcare staffs' role in providing such spiritual care (Romeiro et al. 2017; Egan et al. 2011). Current evidence suggests that while health carers may be aware that patients have spiritual needs, they are lacking in confidence and at times, feel ill-equipped to deal with these concerns (Keenan 2017; Egan et al. 2011). (Keenan 2017) adds to the debate by suggesting that carers may sometimes confuse religion and spirituality and in addition, some may question the relevance of spiritual care. Keenan suggests that nurses need to develop competence in spirituality in health care by deepening their knowledge of various belief systems and supports and knowing when to incorporate a multidisciplinary team approach (Keenan 2017). Evidence to address spiritual health care needs can be developed by knowing and appreciating a patient's personal spiritual understanding, beliefs and practices. A lack of health care practitioners' confidence in this field is displayed in comments such as:

"People are too scared to show any religious or spiritual leaning. It is frowned upon. Religion is also unpopular, not in vogue. You are thought of as weird. You have to be very careful to express or show spirituality, which is a sad reflection on society" (Egan et al. 2011, p. 13).

This comment also highlights the interesting perspective on ethical issues related to spiritual care that also arises within this issue. The need to address spiritual care is advocated in several national and international healthcare policies (Romeiro et al. 2017; Egan et al. 2011), thus not providing this care, or providing substandard care is an ethical issue. Furthermore, there needs to be caution when attempting to address spiritual needs in healthcare, as (Keenan 2017) points out as some people may not wish to confront this issue, perhaps due to a lack of confidence. The pastoral care workers that provided spiritual-based dietary advice for young people in Patel et al. study highlighted these ethical concerns (Patel et al. 2017). These trainers felt out of their depth dealing with some of the existential and emotional issues that could arise as a request of addressing this particular topic (Patel et al. 2017). Keenan (2017) thus calls for attention to spiritual safety, spiritual vulnerability, and spiritual risk in healthcare. In this piece, Keenan acknowledges the notion that spirituality has religious connotations and may provoke conflict for some (Keenan 2017). Keenan considers that health care providers may question the relevance of spirituality in health care, thereby causing gaps in care and he questions the moral implications of this (Patel et al. 2017). Thus a rigorous approach to assessment, planning and managing spiritual needs in health care underpinned by best available evidence and informed by the patient is required (Keenan 2017). Keenan proposes a set of questions that may be useful in determining personal levels of spiritual safety, underpinned by a person-centered approach (Keenan 2017). In adopting a person-centered approach, spiritual needs may be addressed by knowledge of the patient's personal spiritual understanding, beliefs and practices (Keenan 2017). Evidence to support spiritual care assessment, management and planning begins with patients' understanding and expression of what they want and need in terms of spiritual care within each particular clinical setting (Keenan 2017). This may be supported and informed by families when the patient needs help in articulating their needs for whatever reason. To address spiritual vulnerability, risk, and distress, a multidisciplinary approach is required and health carers need to understand and develop competencies in spirituality and in spiritual health care practice (Keenan 2017). There is also 
an ethical balance in promoting safety by maintaining trust and diminishing fear, while acknowledging risk while providing spiritual care (Pike 2017). Reassurance in some settings about patients' fear of death needs to be underpinned by honest and realistic information and not necessary viewed as an existential issue or one that can easily be resolved through spiritual means (Pike 2017).

\subsection{Differing Perspectives Spiritual Care}

While spiritual care is generally understood to be fundamental to palliative care provision there are still limited understandings of the nature of spiritual distress experienced by these patients and how this differs from sadness or depression (Velosa et al. 2017). Velosa et al. (2017) found a 23\% prevalence of spiritual distress and $23 \%$ prevalence of depression among 30 patient, with some $(13 \%)$ experiencing both. Spiritual distress is characterised by a lack of meaning in life, and more research is needed to determine the prevalence of spiritual distress among healthcare recipients and how to tackle this. Of note in this study is a relationship between alcoholism and spiritual distress while the latter was not associated with depression (Velosa et al. 2017). This indicates that there are still cohorts of patients, beyond those traditionally thought to have spiritual needs [i.e., the religious and the dying] that could benefit from spiritual care provision (Velosa et al. 2017). Indeed spiritual and religious care practices have been identified across large studies as having a positive impact on reduction of alcohol intake (Barte et al. 2010). Similarly unique in approach is Patel et al. (Patel et al. 2017) study reporting on an evaluation of a three-month feasibility study testing a UK Christian-based intuitive-eating programme in a church $(n=18)$. Results showed a range of indicators, from mental well-being to Body Mass Index (BMI), improved post-intervention. The participants found the spirituality component of the intervention to be appropriate and engaging. As well as reducing fat intake, there was a spiritual well-being improvement, as measured by Spiritual Well-Being Scale. Nine-month follow up data from baseline found no sustained weight reduction; however, improvements were retained in uncontrolled eating, emotional eating, mental well-being and anxiety. Of note, intuitive eating improvements remained at the six-month follow-up. These statistical analyses are quite limited due to the sample size, but as a feasibility study, the intervention shows great potential. Intuitive eating is implicitly spiritual in the broadest sense (Egan et al. 2011) given its focus on increased awareness. It is an excellent alternative to simply dieting by reducing intake, which mostly fails (Barte et al. 2010), and this intervention takes a salutogenic approach focusing on Christian wellness principals. Further, as a 'train the trainer' approach, the intervention empowers community to become involved in health promotion as opposed to a programme that is facilitated solely by healthcare professionals. As a health education intervention (10 sessions), combing it with an environmental or policy component could also address the growing obesogenic environment (Golden and Earp 2012).

Fulford's (2017) paper is a rich reflection on the opportunity for healthcare professionals to be authentic witnesses to the inner world of suffering of the patients who arrive to general practice settings. Concomitantly the paper challenges general practitioners to be reflective practitioners in the face of the suffering being witnessed. The theoretical foundations of the therapeutic use of self in the relief of the inner suffering of another person in illness are drawn from Kearsley (2010). Spirituality is the thread of connection in this theoretical foundation since it is that capacity of an individual to seek and express insight into the mysterious realities at work in the concrete facts of life. This notion of spirituality in the paper is embedded in the work of (Frankl 2006), a Jewish psychiatrist who, though he was incarcerated in the concentration camp at Auschwitz, survived. He attributed his survival to the ability to find meaning in the midst of appalling suffering. The work on Elisabeth Kubler-Ross, which identified the stages of finding meaning in the face of tragedy, is also employed as a theoretical foundation. The test for the theoretical foundations set out by the author is an encounter with patients who are carriers of early wounds and suffering from childhood. One common element in such an encounter is that they often complain of unexplainable symptoms. In the US Felitti and Anda (2010) were the first to categorise the importance of adverse childhood experiences ACEs for public health. The hiddenness of ACEs means that as general practitioners strive to bear witness on behalf of patients 
who are bearers of $\mathrm{ACE}$, they may increase their own risk of compassion fatigue and burn-out since their own unconscious personal history of ACE may be triggered-given the poor knowledge of this condition which has existed up to this time.

Pike (Pike 2017) reports on part of her PhD study into spirituality in the context of day surgery. In her paper she reports on 13 carers' (nurses, medics and pharmacists) perceptions of day surgery practice. Interviews reveal that "fear of the unknown [was believed to be] one of the greatest fears of the patients" (Pike 2017, p. 4). This fear is acknowledged as a central concept in driving meaning making in this context. In supporting and alleviating this fear, particularly fear of death during anaesthetic, the respondents' actions in terms of caring for the anxious patient were interpreted as spiritual care.

One central emerging theme from the study was "supporting the patient by being with them" (Pike 2017, p. 8). Pike cites Miner-Williams (Miner-Williams 2006) who identifies 'being with' as giving care spiritually. Caring spiritually, by being emotionally present for the other, reflects these nurses' pragmatic approach to caring in context. This paper successfully identifies emotional human interconnectedness, here identified as compassion and trust, as meaningful to both carers and the cared for. These carers identified human connection, being with and building relationships of trust, as most efficacious in identifying and addressing the non-physical or spiritual needs of day surgery patients. The intention of the carer is to connect with the whole person and give them grounds to trust not only the carer but also the health care system. This intention to trusting human connection in the practice of holistic care is interpreted as a form of loving. Despite the short term nature of day surgery, Pike reports carers' recognition that even within the limited time frame of day surgery, spiritual care is possible, indeed essential (Pike 2017). Thus spiritual needs and the need to provide spiritual care arises in a variety of healthcare settings, and these needs [and sometimes the subtle addressing these needs] can go sometimes unnoticed to care givers who are expert at providing holistic, compassionate and subtle care. (Keenan and MacDermott 2016, p. 3) for example had a surprising finding while interviewing nurses who had provided end of life care for children with intellectual disability as they found a subtheme of prayer/religion that enabled families to "focus on the positive".

\subsection{Nurses/Midwives and Spiritual Care}

Many articles on spirituality deliberate the benefits of spirituality care for patients. (Keenan and MacDermott 2016) paper takes a different approach. This qualitative descriptive study adds to the sporadic evidence on spiritual needs of nurses. Specifically they explored needs of nurses caring for intellectually disabled children who have died. The paper highlights that these nurses experience grief when managing dying, death and bereavement (Keenan and MacDermott 2016). Their findings support spirituality as an effective strategy used to deal with this grief. The use of spirituality helps them make sense of the death of a child, to manage nurses' experienced grief, to provide support to a colleague and to frame the service nurses provide (Keenan and MacDermott 2016). This draws attention to the value of using spirituality in the context of professional support (Keenan and MacDermott 2016). Whilst highlighting that spirituality correlates to a lower level of burnout in nurses. Thus a valuable point raised is that spiritually enhances nurses' mental well-being and professional care (Keenan and MacDermott 2016). In contrast, a point of interest in this paper is a discussion regarding nurses' practice being a secular age. This may lead to nurses shying away from identifying the spiritual needs of others and not respond appropriately, potentially leading to omission of spirituality care (Keenan and MacDermott 2016). They suggest that education is provided to staff to gain understanding of the influence and impact of religion on peers. They also suggest that professional nursing regulatory bodies and organisations need to expand their guidelines and references on spirituality beyond patient concerns to include spiritual care for staff (Keenan and MacDermott 2016).

Romeiro et al. (2017) paper supports nurses and midwifes providing a spiritual dimension when giving holistic care to infertile couples. They highlight infertility is a growing concern, affecting some 19.2 million couples worldwide especially as many couples are now delaying starting a family children due to career, educational and financial pressures. Infertile couples are a vulnerable group as they are 
required to undergo various investigations interventions and procedures from a variety of specialists in their quest to conceive a child. A fragmented approach to caring for couples has been presented in the literature with many couples reporting insensitiveness and an absence of connectedness being displayed by health professionals when interacting with them. There is a greater emphasis reported on interventions related to the physical condition and treatments with patients as opposed to their emotional, psychological and spiritual needs. Key areas of neglect include poor communication lack of information, unrealistic portrait of hope, difficulty accessing care, support, and empowerment (Romeiro et al. 2017). Infertility can affect couples sense of wellbeing and cause suffering which may lead them to question the meaning and value of life. There is a need to deliver a more holistic care to these couples that includes sensitively addressing couples' values and beliefs. Spiritual care needs to be included are part of holistic care for all infertile couples as spirituality spans across all the lifespan. There is an onus on nurses and midwifes to develop evidence based knowledge and care models to ensure infertile couples are afforded high quality holistic care which includes spiritual care during this phase of the couples life.

\subsection{Teaching Spiritual Care}

The notion of how educators prepare undergraduate students to best develop holistic caring, learn and deliberate meaningful connections is also explored in this issue (Elhammoumi and Kellum 2017). The skills required supporting professional nursing practice that embrace understanding the human condition and patients illnesses are explored by (Elhammoumi and Kellum 2017). This is done through consideration of the inclusion and use of visual art programmes to develop students' skills of interpersonal connectedness. Whilst the literature demonstrates a evidential interest in the area, the degree to which arts is linked, contemplated and indeed used by educators as a means of progressing aesthetic knowing in nursing is limited (Elhammoumi and Kellum 2017). (Elhammoumi and Kellum 2017) examined the state of the arts in nursing education and considered recent innovative art developments and contributions from 13 studies (3 quantitative, 10 qualitative) undertaken by educators in Sweden, Ireland, UK and US. Fundamentally, findings from the studies viewed visual art as a lens and vector through which students can develop theoretical and critical thinking in nursing. Notable proposed benefits of arts based approach; incorporate knowledge and connectivity of objective and subjective life worlds of patients, thus understanding patient's realities and needs. Other stated art benefits include students becoming increasingly self-aware, 'seeing' patients diverse interpretations with a view to building interpersonal relationships and comprehending patients lived experience that consider caring and suffering as part of understanding human illness and the human condition (Innskeep and Lisko 2001). Visual art experiences help students to 'bridge' and make meaningful connections to patients through reflection, thus improving communication and clinical skills observations, degree of patients symptomology, meeting patients' needs and developing structured learning to empathetic nursing aspects (Elhammoumi and Kellum 2017). Moreover, visual art facilitates students to develop professional foundations of nursing and shape their professional identity through scaffolding aligned to reflection (Elhammoumi and Kellum 2017). A key element of arts based approach helps students to develop meaningful spiritual approaches, skills and needs (Elhammoumi and Kellum 2017). The art of nursing clearly demands educators to consider creative approaches and art strategies to help students develop holistic awareness and understandings of nursing. Utilization of the arts needs to be treated with the same respect and status aligned to science of nursing, as human caring cannot be nurtured 'in an education that is devoid of arts or humanities'. Whilst this paper is written from an international perspective, US nursing education programmes value and have a particular focus on liberal arts and humanities and aesthetic patterns of knowing within baccalaureate nurse education programmes. This is clearly not the case in Ireland or indeed some of our other European counterparts where the nursing education focus lies within empirical, ethical aspects of knowing with some personal aspects. 


\section{Looking Forward}

Addressing peoples' spiritual needs, while receiving healthcare, by connecting with them, supporting their meaning-making, connections and transcendence, can alleviate suffering and provide a sense of wellbeing that may help clients deal with adversity (Golden and Earp 2012; Felitti and Anda 2010). Spiritual care is person-centred and usually provided on a one-to-one basis (Miner-Williams 2006; Innskeep and Lisko 2001). Spirituality involves ones belief system about personal identity, purpose and meaning, what it means to be human to live in a meaningful and a moral way (NHS Education for Scotland 2009). This issue supports the need to examine various aspects of spiritual care across diverse healthcare settings and outline the potential contribution of spirituality to public and population health. As such spirituality ought not to be siloed within end of life care only rather its potential contribution to healthcare needs to be explored across the spectrum of human conditions.

Acknowledgments: The authors would like to thank the School of Nursing and Midwifery Trinity College Dublin who accommodated the conference. We would like to acknowledge the kind support of Jeni Ryan, BA MA Administrative Office, Conference Organizer, School of Nursing and Midwifery, Trinity College Dublin who supported the organization and management the 2016 conference.

Author Contributions: F.T. and W.M., guest editors for the Special Issue. F.T., R.E., B.F., Y.M., C.O., V.B., J.W., K.N. and W.M., developed of the intellectual content of the paper. F.T. finalised the paper.

Conflicts of Interest: The authors declare no conflict of interest.

\section{Abbreviations}

ROI

Republic of Ireland

\section{References}

Barte, J., N. Ter Bogt, R. Bogers, P. Teixeira, B. Blissmer, T. Mori, and W. J. Bemelmans. 2010. Maintenance of weight loss after lifestyle interventions for overweight and obesity, a systematic review. Obesity Review 11: 899-906. [CrossRef] [PubMed]

Egan, Richard, MacLeod Roderick, Chrystal Jaye, McGee Rob, Baxter Joanne, and Peter Herbison. 2011. What is spirituality? Evidence from a New Zealand hospice study. Mortality 16: 307-24. [CrossRef]

Elhammoumi, Cheryl V., and Barbara Kellum. 2017. Art Images in Holistic Nursing Education'. Religions 8: article 103.

Felitti, Vincent J., and Robert F. Anda. 2010. The Relationship of Adverse Childhood Experiences to Adult Medical Disease, Psychiatric Disorders, and Sexual Behavior: Implications for Healthcare. In The Hidden Epidemic: The Impact of Early Life Trauma on Health and Disease, 1st ed. Edited by Ruth A. Lanius and Eric Vermetten. Cambridge: Cambridge University Press, pp. 77-88.

Frankl, Viktor E. 2006. Man's Search for Meaning. Boston: Beacon Press.

Fulford, William. 2017. Hidden Suffering and the Effects of Adverse Childhood Experiences. Religions 8: article 31. [CrossRef]

Golden, Shelley D., and Jo Anne L. Earp. 2012. Social Ecological Approaches to Individuals and Their Contexts: Twenty Years of Health Education \& Behavior Health Promotion Interventions. Health Education Behavior 39: 364-72. [PubMed]

Innskeep, Sandra, and Susan Lisko. 2001. Alternative clinical nursing experience in an art gallery. Nurse Educator 26: 117-19. [CrossRef]

Kearsley, John H. 2010. Therapeutic Use of Self and the Relief of Suffering. Cancer Forum 34: 1-4.

Keenan, Paul Michael. 2017. Spiritual Vulnerability, Spiritual Risk and Spiritual Safety-In Answer to a Question: 'Why Is Spirituality Important within Health and Social Care?' at the 'Second International Spirituality in Healthcare Conference 2016-Nurturing the Spirit.' Trinity College Dublin, The University of Dublin. Religions 8: article 38. [CrossRef]

Keenan, Paul Michael, and Ciara MacDermott. 2016. Prayer and Religion-Irish Nurses Caring for an Intellectually Disabled Child Who Has Died. Religions 7: article 148. [CrossRef] 
La Cour, Peter, and Niels Hvidt. 2010. Research on meaning-making and health in secular society: Secular, spiritual and religious existential orientation. Social Science and Medicine 71: 1292-99. [CrossRef] [PubMed]

Miner-Williams, Denise. 2006. Putting a puzzle together: Making spirituality meaningful for nursing using an evolving theoretical framework. Journal of Clinical Nursing 15: 811-21. [CrossRef] [PubMed]

NHS Education for Scotland. 2009. Spiritual Care Matters: An Introductory Resource for All NHS Scotland Staff. Edinburgh: NES.

Patel, Riya, Deborah Lycett, Anne Coufopoulos, and Andy Turner. 2017. A Feasibility Study of Taste \& See: A Church Based Programme to Develop a Healthy Relationship with Food. Religions 8: article 29.

Pike, Joanne. 2017. Searching for the Hidden: A Phenomenological Study Exploring the Spiritual Aspects of Day Case Surgery from Staff Perspectives. Religions 8: article 15. [CrossRef]

Romeiro, Joana, Sílvia Caldeira, Vivienne Brady, Jenny Hall, and Fiona Timmins. 2017. The Spiritual Journey of Infertile Couples: Discussing the Opportunity for Spiritual Care-Implication for Religious and Spiritual Care. Religions 8: article 76. [CrossRef]

Spirituality Research and Innovation Group. 2016. First International Conference of Spirituality in Healthcare held in Dublin. Nurturing the Spirit. Available online: http:/ / nursing-midwifery.tcd.ie/SIG/nurturingthespirit_ conf2016.php (assessed on 30 August 2017).

Velosa, Teresa, Sílvia Caldeira, and Manuel Luís. 2017. Depression and Distress: A Cross Sectional Study. Religions 8: article 156. [CrossRef]

Weathers, Elizabeth, Geraldine McCarthy, and Alice Coffey. 2015. Concept analysis of spirituality: An evolutionary approach. Nursing Forum. Available online: http:/ / onlinelibrary.wiley.com/doi/10.1111/nuf.12128/epdf (accessed on 18 November 2015).

(C) 2017 by the authors. Licensee MDPI, Basel, Switzerland. This article is an open access article distributed under the terms and conditions of the Creative Commons Attribution (CC BY) license (http:/ / creativecommons.org/licenses/by/4.0/). 